\title{
Strokes and Head Injury
}

\author{
A. BLAU AND J. C. RICHARDSON
}

SUMMARY: This is a report of a series of patients who suffered major cerebral hemorrhage or infarction complicating industrial head injuries. The variable importance of trauma and of pre-existing vascular disease is exemplified. Accuracy of assessment of such complex problems is facilitated by modern applied neuroscientific techniques.

RESUME: Nous présentons une série sélectionnée de patients ayant subis une hémorragie cérébrale majeure ou un infarctus cérébral à la suite d'une blessure crânienne acquise lors d'un accident industriel. L'importance relative, et variable $d u$ traumatisme et de la maladie vasculaire pré existante est illustrée. Les difficultés d'évaluation de tels problèmes complexes sont diminuées grâce aux techniques neurologiques modernes.

From the Hospital and Rehabilitation Centre of the Workmen's Compensation Board of Ontario, 115 Torbarrie Road, Downsview M3L IG8.

Reprint requests to: Dr. J. C. Richardson, 170 St. George Street, Toronto, M5R 2M8, Canada.
The purpose of this report is to discuss a group of patients with head injuries of varying severity, followed by gross cerebral vascular accidents of hemorrhagic or thrombotic nature.

With cranial trauma, the diagnosis and prognosis is no longer limited to conceptions of cerebral concussion, laceration, surface hemorrhage, and fractures. Recent neurosurgical, neuropathological, and neuroradiological studies have emphasized other factors, such as brain swelling of different types, metabolic disorders, hypoxia, and ischemia from vascular damage. There is a wealth of related medical literature. Walpole Lewin surveyed the vascular lesions of head injuries in 1968 and discussed current knowledge and management of severe head injuries in the 1975 Victor Horsley lecture.

The relation of head injury to rupture of non-traumatic cerebral aneurysm is mentioned in various older reports and in the cooperative study reported by Locksley (1966). Increased awareness of traumatic intracranial aneurysms is mentioned by Smith and Bardenheier (1968), Acosta et al. (1972), Benoit and Wortzman (1973) and Jackson et al. (1976). Traumatic intracerebral hematomas are recorded by Larson and Mittelpunkt (1965), Jamieson and Yelland (1972), and De Vet (1976). Many clinical and pathological papers deal with injuries to the internal carotid artery intra- and extracranially-Hockaday (1959), Houck et al. (1964), Hollin et al. (1966), Mastaglia et al. (1969), Schneider et al. (1972).

Accurate diagnosis and full understanding of these vascular lesions is of vital importance in the early management of head injuries. In this study, we are more interested in the later assessment regarding long term prognosis and rehabilitation. In legal, pension, and insurance settlements, it is important to differentiate and apportion the neurological disability from strokes due to vascular disease or malformation from those due to blood vessel injury.

The neurological clinic of the Workmen's Compensation Board Hospital and Rehabilitation Centre, Downsview, Ontario, in operation for the past fourteen years, has provided an extensive and unique opportunity to study and follow a large series of head injured workmen. The pertinent information is derived from study of the early reports, nearly all from special neurosurgical units, and by extensive repeated late neurological, psychiatric, psychological, and other consultations.

Among 431 patients admitted with head injuries from industrial accidents in the years 1972 to 1976 , there were 22 examples of major cerebral infarction or hemorrhage.

1) Hemorrhage

a) Ruptured Aneurysm $\quad-4$

b) Arteriovenous Malformation -1

c) Intracerebral Hematoma $\quad-8$

2) Infarction

a) Internal Carotid Artery Occlusion

b) Middle Cerebral Artery

c) Vertebrobasilar

\section{INTRACRANIAL ANEURYSMS}

Case 1. A 32 year old plumber's assistant fell 5 feet from a ladder, striking his right temporal region and was unconscious for two minutes. He was sent home from a hospital emergency department but four days later developed headache, seizures, and left hemiparesis. A large saccular anterior communicating artery aneurysm and frontal lobe hematoma were found. $\mathrm{He}$ was treated surgically and survived with moderate residual disability.

It was assumed that the minor blunt head injury caused rupture of a preexisting thin walled berry aneurysm through force transmitted from the 
blow, or possibly transient elevation of blood pressure or other hemodynamic changes.

Case 2. On October 9th, 1974, a 17 year old boy fell 30 feet from a roof where he was working and admitted to hospital in a deep stupor. There were no obvious surface abrasions or lacerations and the skull $\mathbf{x}$-ray was normal. He gradually recovered full consciousness over a period of six days and was discharged to his home October 26th. Two days later he developed headache and confusion and became steadily more stuporous. On readmission to a university hospital neurosurgical unit, there was left ocular ptosis, mild left hemiparesis, early papilledema, and diplopia.

Arteriography showed a large hematoma in the right frontal lobe and left pericallosal spherical aneurysm. At surgery, a giant sized thin walled multilocular aneurysm arising from the anterior cerebral artery at the pericallosal-callosomarginal junction was found. It was successfully clipped. A large partially liquefied blood clot was evacuated from the frontal lobe.

He survived without severe dementia or paralysis, but with considerable personality change.

This was probably a traumatic aneurysm caused by injury to the artery wall, perhaps against the sharp edge of the falx, and rapid enlargement with extensive intracerebral hemorrhage. It remains possible, but unlikely, that this was a pre-existing aneurysm with rupture causing the fall, or with rupture caused by the injury.

Case 3. A 39 year old diesel mechanic working under a trailer bumped his head, a mild but jarring and painful blow. Three days later he had a subarachnoid hemorrhage. A large left middle cerebral aneurysm was surgically clipped. Postoperative extra-dural hemorrhage occurred and there was residual dysphasia and hemiparesis.

This claim was accepted on the premise of rupture of the pre-existing saccular aneurysm precipitated by minor head injury.

Case 4. A 21 year old factory worker suffered a minor non-concussive head injury. There was persistent headache though he returned to work the next day. He developed a partial 3rd cranial nerve palsy and arteriography showed bilateral internal carotid artery aneurysms. These were both clipped surgically. There was no major hemorrhage. The patient suffered moderate residual mental impairment and seizures.

The immediate and persisting headache and the early development of a 3rd nerve palsy validated the conclusion that the blow to the head led to enlargement of a carotid berry aneurysm.

Three of these four cases of intracranial aneurysm exemplify the occasional factor of head injury of mild severity precipitating rupture and hemorrhage from a pre-existing developmental berry aneurysm. These aneurysms, which are the commonest cause of spontaneous subarachnoid hemorrhage, usually rupture during ordinary activities or with exertion. Head trauma is a factor in a small proportion (2.8\% in the cooperative study based on 2,288 aneurysms, by Locksley). The fourth example, Case 2 , is different and quite likely a true traumatic aneurysm caused by the severe blunt head trauma. Recent reports have indicated a larger incidence of traumatic intracranial aneurysms than previously recognized. These are usually located on small peripheral cerebral arteries or on larger vessels, such as the carotid, in basal areas adjacent to bony fractures. The demonstration of trauma as a cause of pericallosal aneurysms, and the rarity of non-traumatic aneurysms in this region, favor the acceptance of trauma as the pathogenesis in this case.

\section{Traumatic Intracerebral Hemorrhage}

Cerebral arteriovenous malformation (A.V.M.) is a poor second to berry aneurysm as a cause of subarachnoid or non-hypertensive intracerebral hemorrhage, though relatively commoner in children. The bleeding usually occurs without head injury. However, there are instances of bleeding from an A.V.M. following minor or major cranial trauma. There are two examples in the recent Ontario civil court reports in which persons received substantial awards for cerebral hemorrhages from angiomas following minor head injuries in motor vehicle accidents.

There was one example in this series

Case 5. A 22 year old construction worker was struck on the head by falling timber on April 6th, 1968. He was dazed but carried on working after a short rest. Within a few hours he became aware of numbness and tingling of his left arm. This persisted intermittently with some weakness. On August 5th, 1968, he developed severe headache with weakness and confusion. Left hemiparesis was noted and arteriography showed a large arteriovenous malformation in the central region of the right cerebral hemisphere. There was an intracerebral clot which had extended into the right lateral ventricle. The clot was evacuated and the angioma successfully excised. It had one main feeding pericallosal artery.

It seems reasonable that this workman's cerebral hemorrhage from the A.V.M. was initiated by the mild blunt head injury with immediate small post-traumatic hemorrhage contributing to the severe and damaging hematoma four months later. Re-examined in 1977, he showed residual mental change, hemiparesis and seizures, though able to perform light work and play his guitar.

This clinical group lacked examples of trauma inducing hemorrhage from other demonstrable pre-existing arterial or venous diseases. Hypertensive vascular disease remains the commonest cause of primary intracerebral hemorrhage, though much reduced by hypotensive drug therapy. Violent physical effort, and occasionally a blow to the head, may precipitate such an hypertensive brain hemorrhage. Similarly, there are reported examples of hemorrhage into cerebral tissue from telangiectases and these may explain those occasional cases developing after head trauma.

Intracerebral hemorrhage does occur with blunt head injury commonly as result of surface contusion, but also without such contusion or meningeal bleeding. In this survey, our experience is limited but worthy of discussion. There were 93 patients (of the 431 head injuries) with gross intracranial hemorrhage, chiefly meningeal. There were 17 intracerebral hematomas, 6 accompanying major cerebral contusions and 9 concurrent with extra- or subdural bleeding. There remained 2 examples of pure isolated traumatic intracerebral hemorrhage.

Case 6. In June, 1969, this 44 year old man fell from a ladder 8 to 10 feet, striking his head in the right parietal region. There was a lucid interval of 4 to 5 hours, after which he became comatose with a left hemiplegia. A right parietal deep hematoma was recognized and 40 c.c. of dark liquid blood was surgically evacuated. No surface contusion or meningeal hemorrhage was present. Carotid angiography showed no aneurysm or A.V.M. He improved but three days later relapsed and further clot 
was removed. He has remained severely disabled by hemiparesis as well as speech impairment and dementia.

Case 7. A 39 year old man known to be alcoholic and mildly diabetic, fell 14 feet from a ladder suffering an occipital scalp laceration without loss of consciousness. After being seen at hospital he was sent home. Eight days after injury he was hard to rouse and was admitted to hospital where arteriography showed a pronounced right to left shift and a right temporal mass lesion. Through a burr hole, a liquefied hematoma of 30 c.c. was evacuated. He gradually improved, but was left with moderate dementia and hemianopia. He has continued receiving a W.C.B. pension with a rating of $80 \%$ permanent disability.

The occurrence of hemorrhage within the cerebral hemisphere as an early direct effect of blunt head injury is amply reported, though less common than meningeal bleeding.

The case just reported (number 7), with intracerebral hemorrhage occurring eight days after minor head injury, recalls delayed traumatic apoplexy or Spät-Apoplexie as pointed out by Bollinger (1891) and described in a few subsequent papers (Symonds, 1940; Morin and Pitts, 1970). The appraisal of these cases in the past has depended on clinical and pathological observations. The advent of computerized tomographic (C.T.) scanning will greatly enhance the accuracy of diagnosis. Perhaps small traumatic aneurysms may be the cause in some areas.

A striking example of Spät-Apoplexie was studied by one of us (J.C.R.) many years ago and never published, though presented to the Montreal Neurological Society in 1946. A 30 year old worker in a chemical plant suffered a blast injury in a chemical explosion. He was dazed and had tinnitus and dizziness with early recovery until nine days later he suffered apoplexy which proved fatal. A massive hemorrhage in the brainstem and 4th ventricle was found. There was no sign of vascular disease or malformation.

\section{Post-Traumatic Ischemic Cerebral In- farction}

These patients have had major infarct strokes following head trauma. There were 5 with involvement of the internal carotid artery, 3 of the middle cerebral and 1 vertebrobasilar.
Case 8. A 46 year old driver went over a cliff in a tractor-trailer and suffered multiple cranial and facial fractures as well as severe diffuse brain injury. He had a right hemiparesis and left blindness and angiograms revealed occlusion of the left internal carotid artery with no filling above the base of the skull. Intracavernous carotid thrombosis was diagnosed. There was initial recovery with temporary resumption of truck driving, but he regressed to an unemployable state with some dementia, vertigo, and mild paresis.

Case 9. A man aged 44 , caught his clothing in a lathe and constricted his neck. One hour later he developed right hemiplegia with dysphasia and hemianopia. Angiograms showed occlusion of the left internal carotid artery in the neck just above the bifurcation. Surgical exploration showed lengthy thrombosis and little recovery occurred.

Case 10. A man aged 65 fell 10 feet from a ladder striking his occiput and suffered a linear fracture and severe concussive brain injury. After brief coma, he was confused. The next day, he developed a left hemiplegia and angiograms showed thrombosis at the site of an atheromatous plaque and stenosis of the right internal carotid artery at its origin. There was eventual moderate recovery.

Case 11. A man, aged 20, was injured in a fall of 15 feet. He sustained a blunt head injury with retrograde amnesia of one hour and post-traumatic amnesia of one week and a basal skull fracture. There was immediate coma with left hemiparesis. Angiography showed no filling of the right internal carotid artery above the sella. Excellent recovery occurred, leaving a mild left hemiparesis.

Case 12. This 56 year old man jarred against a metal post and the pipe he was smoking was driven back to cause a large hematoma in the left tonsillar area. This was accompanied by thrombosis of the left internal carotid artery shown by angiography. The initial fairly severe right hemiplegia and dysphasia gradually subsided.

Here was an example of direct trauma to the internal carotid artery by a pipe stem being driven back into the throat. Similar accidents in children falling with objects in their mouths have been reported (Pitner, 1966; Editorial, 1966).

Case 13. A man, aged 29, was struck by a hammer on his head, causing a left parietal depressed fracture and a brain laceration $2 \mathrm{~cm}$. in depth. This was treated surgically. The following day he developed a right hemiplegia and aphasia. There was gradual recovery, leaving a paretic right hand and epilepsy.

Angiography was not done and the diagnosis was presumably a post-operative middle cerebral artery thrombosis or embolism.

Case 14. A man, aged 49 , on June 21 st, 1972 , was struck on the head by a baseball bat and suffered a linear right occipital fracture extending into the temporal squama. There was no retrograde amnesia and the post-traumatic amnesia lasted three minutes only. He suffered headache and nausea until September, 1972, but carried on at work.

On November 21st, 1972, he wakened with headache and a left sided ataxia. Right and left retrograde brachial angiography showed nothing abnormal, except some narrowing at the origin of the right vertebral artery.

This was probably a vascular lesion of the left cerebellum, either infarct or hemorrhage. There is reasonable likelihood of an initial small traumatic cerebellar contusion and hemorrhage with delayed extension. (Delayed traumatic apoplexy.)

Case 15. This 54 year old workman had suffered a myocardial infarct five years previously and there was a family history of vascular disease. While pushing a food truck he slipped on the wet floor and fell striking the back of his head. There was a brief period of coma from which he roused in some hours, but he was left with a severe disabling left hemiplegia.

Without special diagnostic procedures one can only speculate that he suffered a deep right cerebral hemisphere infarct from thrombosis or embolism of the middle cerebral artery. The significant moderate blunt head injury must be the cause.

Case 16. This 48 year old bartender was involved in a scuffle in which he banged his head on a table and seemed comatose for a few minutes. Directly he was found to have a left hemiplegia. Angiography showed considerable narrowing of the right common and internal carotid arteries. A diagnosis of cerebral infarction in the middle cerebral distribution, probably small vessel occlusion and possibly traumatic was suggested.

\section{CONCLUSIONS}

This group of nine patients with major intracranial arterial occlusions following accidental blunt head injuries includes examples of direct arterial trauma, and others in which trauma is a secondary cause of occlusion of an 
atheromatous vessel. Recent reports aided by angiography have clarified the mechanisms of direct arterial injury and thrombosis. The internal carotid artery is vulnerable at its entry into the skull and at other sites where there are proximal bony edges and fragments. The basilar and vertebral arteries have been shown to be directly injured with basal posterior fossa fractures. (Simeone and Goldberg, 1968; Shaw and Alvord, 1972). We have not dealt with vertebral artery injury in the neck with cervical vertebral fractures, dislocations, and osteophytes. Other intracranial arteries, such as the anterior cerebral, have been shown to suffer injury from the sharp dural edges of the falx and tentorium.

In this selected group of accidentally head injured men with serious cerebral vascular complications, the accuracy of diagnosis and precision of treatment owes much to cerebral angiography and computed $x$-ray tomography. Three patients with pre-existing berry aneurysms are considered to have suffered hemorrhage after minor head trauma. There was one example of a giant pericallosal aneurysm, presumed traumatic. Traumatic intracerebral hemorrhage has been discussed, with mention of the phenomenon of delayed traumatic apoplexy. Five examples of internal carotid artery thrombosis have been described, three of which were nuchal and two intracranial. Direct trauma was evident in three, whereas in two there was important underlying atheroma. The symptoms of two patients with mid cerebral and cerebellar occlusive infarcts were delayed after minor head trauma but presumably were related to the injuries.

\section{REFERENCES}

ACOSTA, C., WILLIAMS, P. E. and CLARK, K. (1972). Traumatic aneurysms of the cerebral vessels. J. NEUROSURG. 36, 531536.

BENOIT, B. G. and WORTZMAN, G. (1973). Traumatic cerebral aneurysms. J. NEUROL. NEUROSURG. PSYCHIAT, 36, 127-138.

BOLLINGER, O. (1891). Über traumatische Spät-Apoplexie; ein Beitrag zur Lehre von der Hirnerschütterung. Festschr. Rud. Virchow, Berlin 2, 457-470.

DEVET, A. C. (1976). Traumatic Intracerebral Hematoma in: P. J. Vinken and G. W. Bruyn: Handbook of clinical neurology 24, 351-368.

EDITORIAL (1966). Carotid artery occlusion following intraoral trauma. New Engl. J. Med. 274, 799.

HOCKADAY, T. D. R. (1959). Traumatic thrombosis of the internal carotid artery. J. NEUROL. NEUROSURG. PSYCHIAT. 22, 229-231.

HOLLIN, S. A., SUKOF, M. H., SILVERSTEIN, A. and GROSS, S. W. (1966). Posttraumatic middle cerebral artery occlusion. J. NEUROSURG. 25, 526-535.

HOUCK, W. S., JACKSON, J. R., ODOM, G. L. and YOUNG, W. G. (1964). Occlusion of the internal carotid artery in the neck secondary to closed trauma to the head and neck. ANN. SURG. 159, 219-221.

JACKSON, F. E., GLEAVE, J. R. W. and JANON, E. (1976). The traumatic cranial and intracranial aneurysms in $P$. J. VINKEN and G. W. BRUYN: Handbook of clinical neurology. 24, 351-368.
JAMIESON, K. G. and YELLAND, J. D. N. (1972). Traumatic intracerebral hematoma. J. NEUROSURG. 37, 528-532.

LARSON, S. J. and MITTELPUNKT, A. (1965). Posttraumatic intracerebral hematoma. J. TRAUMA. 5, 482-490.

LEWIN, W. (1968). Vascular lesions in head injuries. BRIT. J. SURG. 55, 321-331.

LEWIN, W. (1976). Changing attitudes to the management of severe head injuries. BRIT. MED. J. 2, 1234-1239.

LOCKSLEY, H. B. (1966). Natural history of subarachnoid hemorrhage, intracranial aneurysms and arteriovenous malformations. J. NEUROSURG. 25, 219.239.

MASTAGLIA, F.L., SAVAS, S. and KAKULAS, B. A. (1969). Intracranial thrombosis of the internal carotid artery after closed head injury. J. NEUROL. NEUROSURG. PSYCHIAT. 32, 383-388.

MORIN, M. A. and PITTS, F. W. (1970). Delayed apoplexy following head injury. J. NEUROSURG. 33, 542-547.

PITNER, S. E. (1966). Carotid thrombosis due to intraoral trauma. NEW ENGL. J. MED. 274, 764-767.

SCHNEIDER, R. C., GOSCH, H. H., TAREN, J. A., FERRY, D. J. and JERVA, M. J. (1972). Blood vessel trauma following head and neck injuries. CLIN. NEUROSURG. 19, 312-354.

SHAW, C. M. and ALWORD, E. C. (1972). Injury of the basilar artery associated with closed head trauma. J. NEUROL. NEUROSURG. PSYCHIAT. 35, 247-257.

SIMEONE, F. A. and GOLDBERG, H. I. (1968). Thrombosis of the vertebral artery from hyperextension injury to the neck. $J$. NEUROSURG. 29, 540-544.

SMITH, K. R. and BARDENHEIER, J. A. (1968). Aneurysms of the pericallosal artery caused by closed head trauma. J. NEUROSURG. 29, 551-554.

SYMONDS, C. P. (1940). Delayed traumatic intracerebral hemorrhage. BRIT. MED. J. 1, 1048-1051. 